О. И. Левченко

Информационно-библиотечный центр Института физики твёрдого тела РАН

\author{
Особенности профиля комплектования \\ системы информационно-библиотечных ресурсов \\ научно-исследовательского института \\ (на примере Института физики твёрдого тела РАН)
}

\begin{abstract}
Представлена система информационно-библиотечных ресурсов НИИ. Рассмотрен наиболее динамичный элемент этой системы - блок электронных ресурсов, как собственной генерации, так и других производителей. Предложен профиль их комплектования, использование которого направлено на развитие системы информационно-библиотечных ресурсов НИИ, соответствующей современным информационным потребностям учёных, и на формирование целостной документно-информационной среды конкретного НИИ. В качестве иллюстрации представлен тематико-типологический план комплектования библиотеки Института физики твёрдого тела РАН.
\end{abstract}

Ключевые слова: информационные потребности учёных, тематико-типологический план комплектования, уровни доступа, Институт физики твёрдого тела РАН.

UDC 025.2

\title{
Olga Levchenko
}

Russian Academy of Sciences Institute of Solid State Physics, Moscow Region, Russia

\section{Collection development profile of the research institute's information and library resources (the case study of the Russian Academy of Sciences Institute of Solid State Physics)}

The system of the research institute's library information resources is described. The electronic resources generated both by the institute itself and other producers are characterized as the most dynamic system component. Collection development profile relevant to researchers' current information needs and designed to form uniform document and information environment of the Institute is suggested. 
Keywords: researchers' information needs, research institute's information library resource system, subject typological collection development plan, researcher's distributed workspace.

The most dynamic elements of library resources are electronic documents including resources of own generation (documents, catalogs, directories, databases), and remote resources of external manufacturers. The acquisitions of research libraries, which are embedded into the centralized library systems are carried out through centralized and decentralized channels. Centralized acquisition provides the needs of all libraries and, as a rule, involves a limited number of access points. The access point is the computer of the local area network with the IP-address of computers in the reading room of research library, the use of which is limited by the library's working hours. For example, access from one computer to the centrally acquired resources of the American Chemical Society allows satisfying the requests of the staff of the Institute of Solid State Physics of the Russian Academy of Sciences. But access to basic institute resources, for example, Elsevier, Springer, American Physical Society, American Institute of Physics, you need access from all computers - in the library, laboratory, outside the institute, on a business trip. Separate laboratories require resources of a narrow thematic focus, for example, databases on the X-ray spectra of atoms, molecules, crystals. Therefore, there is a need for decentralized acquisitions. Access to this database provided by the IP-addresses of the X-ray laboratory which performs research of the structures of objects. The decentralized acquisition of remote resources expands the repertoire of subscriptions and increases the number of access points to resources. The main document regulating the acquisition of the Research Institute is the thematic-typological plan. The libraries of research institutes embedded into the structure of the Central Research Library of the Academy of Sciences typically indicate: UDC indexes reflecting the relevance of the publication to the topic of acquisition; types of publications (scientific, educational, reference); the degree of their importance for the library of a particular library (indicated by the numbers $3,2,1$, where 3 is the most important), by which the number of items required for distribution among the libraries of the network is determined.

Деятельность библиотек НИИ ориентирована на удовлетворение информационных потребностей (ИП) пользователей - учёных конкретного института. Мониторинг ИП показывает: для них важно, чтобы информационно-библиотечные ресурсы (ИБР) максимально соответствовали актуаль- 
ным тематическим направлениям научных исследований НИИ, а система ИБР обладала такими качествами, как полнота, надёжность каждого элемента, возможность оперативного получения научной информации, доступность информационных ресурсов.

Этим требованиям отвечает система ИБР, состоящая из фондов печатных и электронных документов по тематике научных исследований института и справочно-поискового аппарата.

Рассмотрим наиболее динамичный элемент этой системы - блок электронных ресурсов, который включает электронные ресурсы и собственной генерации (документы, каталоги, картотеки, базы данных), и других производителей (сетевые удалённые ресурсы). Они различаются по таким признакам, как наличие/отсутствие печатного аналога; уровень (режим) доступа: открытый/ограниченный доступ (подписные лицензионные ресурсы, ресурсы собственной генерации, доступные по локальной сети учреждения и т.д.); ограниченное/неограниченное количество одновременных пользователей ресурса.

Комплектование библиотек НИИ, входящих в структуру централизованных библиотечных систем (ЦБС), осуществляется по централизованным и децентрализованным каналам.

Централизованное комплектование сетевыми электронными ресурсами обеспечивает потребности всех библиотек сети и, как правило, предполагает ограниченное количество точек доступа ${ }^{1}$ к подписным лицензионным ресурсам в читальном зале библиотеки НИИ.

Практика показывает, что сотрудникам института бывает недостаточно доступа к сетевым удалённым ресурсам с компьютеров, использование которых ограничено временем работы библиотеки. Поэтому существует необходимость децентрализованного комплектования на средства НИИ исходя из потребностей учёных. Например, доступ с одного компьютера к централизованно приобретённым ресурсам American Chemical Society и другим ресурсам смежной тематики позволяет удовлетворить запросы сотрудников Института физики твёрдого тела РАН (ИФТТ). Но к таким основным профильным для института ресурсам, как, например, издания Elsevier, Springer, American Physical Society, American Institute of Physics, необходим доступ со всех рабочих компьютеров. А в идеале - с распределённого рабочего места каждого учёного без ограничений по времени: с IP-адресов локальной сети НИИ - в библиотеке, лаборатории, аудитории; вне института,

1 Точкой доступа является компьютер локальной сети НИИ с зарегистрированным у поставщика ресурса IP-адресом. 
например в командировке - с ноутбука, планшета и других персональных мобильных коммуникаторов.

Отдельным лабораториям необходимы ресурсы узкой тематической направленности, например БД по рентгеновским спектрам атомов, молекул, кристаллов. Удовлетворение узкоспециализированных ИП учёных обеспечивается в рамках децентрализованного комплектования. Доступ к БД, организованный с IP-адресов рентгеновской лаборатории, обеспечивает ИП сотрудников, которые проводят исследования структур объектов. Таким образом, децентрализованное комплектование сетевыми удалёнными ресурсами направлено на расширение репертуара подписок и увеличение количества точек доступа к ресурсам.

Основной документ, регламентирующий комплектование ИБР НИИ, тематико-типологический план комплектования. В типовом ТТПК библиотек НИИ, входящих в структуру ЦБС БЕН РАН, указываются:

индексы УДК, отражающие соответствие издания тематике комплектования;

типы изданий (научные, учебные, справочные);

степень их важности для фонда конкретной библиотеки (обозначается цифрами $3,2,1$; где 3 - наиболее важное), по которой определяется количество экземпляров, необходимых ЦБС для распределения между библиотеками сети ${ }^{2}$.

План комплектования ИФТТ РАН является составной частью сводного ТТПК ЦБС БЕН РАН (табл. 1).

2 Бочарова Е.Н.Актуализация сводного тематико-типологического плана комплектования ЦБС БЕН РАН / Е. Н. Бочарова, Е. В. Кочукова, Я. Я. Докторов // Библиосфера. - 2009. № 2. - C. 87-89.

Bocharova E. N. Aktualizatsiya svodnogo tematiko-tipologicheskogo plana komplektovaniya TSBS BEN RAN / E. N. Bocharova, E. V. Kochukova, Ya. Ya. Doktorov // Bibliosfera. - 2009. - № 2. C. 87-89. 
Тематико-типологический план комплектования библиотеки ИФТТ РАН (фрагмент ТТПК БЕН РАН)

\begin{tabular}{|c|c|c|c|}
\hline УДК & Расшифровка индекса УДК & $\begin{array}{c}\text { Тип } \\
\text { издания }\end{array}$ & Важность \\
\hline 004.7 & Сети ЭВМ & $\mathrm{H}+\mathrm{c}+\mathrm{y}$ & 3 \\
\hline 519.6 & $\begin{array}{l}\text { Вычислительная математика. Численный анализ } \\
\text { и программирование }\end{array}$ & $\mathrm{H}+\mathrm{c}+\mathrm{y}$ & 3 \\
\hline $53: 51$ & Математическая физика & $\mathrm{H}+\mathrm{c}+\mathrm{y}$ & 2 \\
\hline $53: 519.6$ & Численные методы. Вычислительная физика & $\mathrm{H}+\mathrm{c}+\mathrm{y}$ & 2 \\
\hline 530 & Основные теории (принципы) физики & $\mathrm{H}+\mathrm{c}+\mathrm{y}$ & 2 \\
\hline $53: 62$ & Техническая физика & $\mathrm{H}+\mathrm{C}$ & 2 \\
\hline 530.182 & Нелинейные явления & $\mathrm{H}+\mathrm{C}$ & 3 \\
\hline 531.3 & Динамика & $\mathrm{H}+\mathrm{c}+\mathrm{y}$ & 2 \\
\hline $531: 530.182$ & Нелинейная механика & $\mathrm{H}+\mathrm{C}$ & 2 \\
\hline 535.31 & Геометрическая оптика & $\mathrm{H}+\mathrm{C}$ & 2 \\
\hline 535.33 & $\begin{array}{l}\text { Спектры в целом. Эмиссионные спектры. } \\
\text { Спектроскопия в целом }\end{array}$ & $\mathrm{H}+\mathrm{c}+\mathrm{y}$ & 3 \\
\hline 537.31 & $\begin{array}{l}\text { Распространение электричества. Электропровод- } \\
\text { ность (в целом) }\end{array}$ & $\mathrm{H}+\mathrm{c}+\mathrm{y}$ & 3 \\
\hline 538.9 & Физика конденсированного состояния & H & 3 \\
\hline 538.91 & Структуры, включая переходы & $\mathrm{H}+\mathrm{c}+\mathrm{y}$ & 3 \\
\hline 538.93 & $\begin{array}{l}\text { Явления переноса в конденсированном состоя- } \\
\text { нии }\end{array}$ & $\mathrm{H}$ & 3 \\
\hline 538.94 & Квантовые жидкости и твёрдые тела & $\mathrm{H}+\mathrm{c}+\mathrm{y}$ & 3 \\
\hline 538.941 & Сверхтекучесть. Жидкий и твёрдый гелий & $\mathrm{H}+\mathrm{c}+\mathrm{y}$ & 3 \\
\hline 538.945 & Сверхпроводимость & $\mathrm{H}+\mathrm{C}+\mathrm{H}$ & 3 \\
\hline 538.95 & $\begin{array}{l}\text { Свойства и явления в конденсированном состоя- } \\
\text { нии (кроме явлений переноса) }\end{array}$ & $\mathrm{H}+\mathrm{C}$ & 3 \\
\hline 538.97 & $\begin{array}{l}\text { Взаимодействие твёрдого тела с элементарными } \\
\text { частицами и излучением }\end{array}$ & $\mathrm{H}+\mathrm{C}$ & 2 \\
\hline 538.975 & $\begin{array}{l}\text { Физика тонких плёнок, нитевидных кристаллов и } \\
\text { дендритов }\end{array}$ & $\mathrm{H}+\mathrm{c}+\mathrm{y}$ & 3 \\
\hline $538.975 \mathrm{~L}-\mathrm{B}$ & Пленки Ленгмюра-Блоджетт & $\mathrm{H}+\mathrm{C}$ & 3 \\
\hline 539.1 & $\begin{array}{l}\text { Ядерная, атомная, молекулярная физика. Физика } \\
\text { элементарных частиц }\end{array}$ & $\mathrm{H}+\mathrm{C}$ & 1 \\
\hline
\end{tabular}


Продолжение таблицы 1

\begin{tabular}{|c|c|c|c|}
\hline Удк & Расшифровка индекса УДК & $\begin{array}{c}\text { Тип } \\
\text { издания }\end{array}$ & Важность \\
\hline 539.16 & Радиоактивность и радиоактивный распад & $\mathrm{H}$ & 1 \\
\hline 539.17 & Ядерные реакции & $\mathrm{H}+\mathrm{C}$ & 1 \\
\hline 539.19 & Физика отдельных молекул & $\mathrm{H}+\mathrm{C}$ & 3 \\
\hline 539.2 & Структура молекулярных систем & $\mathrm{H}+\mathrm{C}$ & 2 \\
\hline 539.26 & Рентгеноструктурный анализ & $\mathrm{H}+\mathrm{C}$ & 2 \\
\hline 539.27 & $\begin{array}{l}\text { Исследование конденсированного состояния } \\
\text { материи при помощи дифракционных и род- } \\
\text { ственных методов (кроме дифракции рентгенов- } \\
\text { ских лучей) }\end{array}$ & $\mathrm{H}+\mathrm{c}+\mathrm{y}$ & 3 \\
\hline 539.3 & Упругость. Деформация & $\mathrm{H}+\mathrm{c}+\mathrm{y}$ & 3 \\
\hline 544 & Физическая химия & $\mathrm{H}+\mathrm{c}+\mathrm{y}$ & 2 \\
\hline 544.1 & Химическое строение вещества & $\mathrm{H}+\mathrm{C}$ & 1 \\
\hline 544.16 & $\begin{array}{l}\text { Зависимость свойств веществ от их атомно- } \\
\text { молекулярного строения }\end{array}$ & $\mathrm{H}+\mathrm{C}$ & 1 \\
\hline 544.452 & Фотохимия & $\mathrm{H}+\mathrm{C}$ & 1 \\
\hline 548 & Кристаллография & $\mathrm{H}+\mathrm{c}+\mathrm{y}$ & 3 \\
\hline 548.73 & $\begin{array}{l}\text { Рентгенографический анализ кристаллов. } \\
\text { Соответствующие свойства }\end{array}$ & $\mathrm{H}+\mathrm{c}+\mathrm{y}$ & 3 \\
\hline 551.52 & Радиация и температура & $\mathrm{H}+\mathrm{C}$ & 1 \\
\hline 621.38 & Электроника & $\mathrm{H}+\mathrm{C}$ & 1 \\
\hline 621.382 & $\begin{array}{l}\text { Электронные элементы, использующие свойства } \\
\text { твёрдого тела. Полупроводниковая электроника }\end{array}$ & $\mathrm{H}+\mathrm{C}$ & 1 \\
\hline
\end{tabular}

В настоящее время, когда система ИБР является полидокументной, в ТТПК необходимо отразить не только тематику, типы изданий и их значение для фондов НИИ, но и ряд других важных параметров, которые играют значительную роль при формировании системы ИБР конкретного НИИ и могут обеспечить её развитие с целью достижения оптимального состава и удобства для пользователя. На наш взгляд, помимо тематикотипологической модели фонда целесообразно создание дополнительной модели ИБР - профиля комплектования, который отражает такие критерии, как форма представления документов (печатная/электронная), уровень (режим) доступа (открытый/локальный), количество точек доступа (читальный зал библиотеки/конкретная лаборатория/все компьютеры локальной сети НИИ), многоканальность (лимитированное/нелимитированное количество одновременных пользователей) (табл. 2). 


\section{Профиль комплектования системы ИБР ИФТТ РАН}

\begin{tabular}{|c|c|c|c|}
\hline \multirow[b]{2}{*}{ Виды изданий } & Форма & Количество & \multirow{2}{*}{$\begin{array}{c}\text { Размещение/ } \\
\text { уровень доступа }\end{array}$} \\
\hline & $\begin{array}{l}\text { печатная (п) / } \\
\text { электронная (э) }\end{array}$ & $\begin{array}{c}\text { экземпляров*/ } \\
\text { точек доступа } * *\end{array}$ & \\
\hline \multicolumn{4}{|l|}{ I. Книги и брошюры } \\
\hline \multicolumn{4}{|l|}{ 1. Научные издания } \\
\hline 1.1. Монографии & II/3 & 1-2/все IP & $\begin{array}{c}\text { ОД/Аб } \\
\text { сервер/лок. }\end{array}$ \\
\hline $\begin{array}{l}\text { 1.2. Собрания сочинений, из- } \\
\text { бранные труды, сборники науч- } \\
\text { ных трудов, в том числе юби- } \\
\text { лейные научные сборники }\end{array}$ & II & 1 & ОД/ЧЗ \\
\hline $\begin{array}{l}\text { 1.3. Материалы научных конфе- } \\
\text { ренций (доклады, тезисы докла- } \\
\text { дов) }\end{array}$ & II/3 & 1/все IP & $\begin{array}{c}\text { ЧЗ } \\
\text { сервер/откр. }\end{array}$ \\
\hline \multicolumn{4}{|l|}{$\begin{array}{l}\text { 1.4. Неопубликованные докумен- } \\
\text { ты }\end{array}$} \\
\hline 1.4.1. Диссертации & II/3 & 1/все IP & $\begin{array}{c}\text { ЧЗ } \\
\text { сервер/откр. }\end{array}$ \\
\hline 1.4.2. Авторефераты диссертаций & II/3 & 1/все IP & $\begin{array}{c}\text { प3 } \\
\text { сервер/откр. }\end{array}$ \\
\hline 1.4.3. Отчёты по проектам, о НИР & II/3 & 1/все IP & $\begin{array}{c}\text { ЧЗ } \\
\text { сервер/откр. }\end{array}$ \\
\hline 1.5. Научные биографии & II & 1 & ОД/Аб \\
\hline $\begin{array}{l}\text { 2. Научно-популярные издания } \\
\text { (монографии, биографии, очер- } \\
\text { ки, тематические сборники) }\end{array}$ & $\pi / 3$ & 1/все IP & $\begin{array}{c}\text { ОД/Аб } \\
\text { сервер/откр. }\end{array}$ \\
\hline \multicolumn{4}{|l|}{ 3. Справочные издания } \\
\hline 3.1. Энциклопедии & II/3 & 1/все IP & $\begin{array}{c}\text { ЧЗ } \\
\text { сервер/лок. }\end{array}$ \\
\hline 3.1.1. Универсальные & II/3 & 1/все IP & $\begin{array}{c}\text { ЧЗ } \\
\text { сервер/лок. }\end{array}$ \\
\hline 3.1.2. Отраслевые & II/3 & 1/все IP & $\begin{array}{c}\text { ЧЗ } \\
\text { сервер/лок. }\end{array}$ \\
\hline
\end{tabular}


Продолжение таблицы 2

\begin{tabular}{|c|c|c|c|}
\hline \multirow[b]{2}{*}{ Виды изданий } & Форма & Количество & \multirow{2}{*}{$\begin{array}{c}\text { Размещение/ } \\
\text { уровень доступа }\end{array}$} \\
\hline & $\begin{array}{l}\text { печатная (п) / } \\
\text { электронная (э) }\end{array}$ & $\begin{array}{l}\text { экземпляров*/ } \\
\text { точек доступа** }\end{array}$ & \\
\hline 3.1.3. Тематические & II/3 & 1/все IP & $\begin{array}{c}\text { ЧЗ } \\
\text { сервер/лок. }\end{array}$ \\
\hline \multicolumn{4}{|l|}{ 3.2. Словари } \\
\hline $\begin{array}{l}\text { 3.2.1. Энциклопедические (от- } \\
\text { раслевые, тематические) }\end{array}$ & $\Pi / 3$ & 1/все IP & $\begin{array}{c}\text { ЧЗ } \\
\text { сервер/ лок. }\end{array}$ \\
\hline $\begin{array}{l}\text { 3.2.2. Языковые (толковые, ор- } \\
\text { фографические) }\end{array}$ & II/3 & 1/все IP & $\begin{array}{c}\text { ЧЗ } \\
\text { сервер/ лок. }\end{array}$ \\
\hline $\begin{array}{l}\text { 3.2.3. Переводные (двуязычные } \\
\text { и многоязычные) }\end{array}$ & $\Pi / 3$ & 1/все IP & $\begin{array}{c}\text { ЧЗ/Аб } \\
\text { сервер/лок. }\end{array}$ \\
\hline $\begin{array}{l}\text { 3.2.4. Терминологические (меж- } \\
\text { отраслевые, отраслевые, темати- } \\
\text { ческие) }\end{array}$ & II/3 & 1/все IP & $\begin{array}{c}\text { ЧЗ } \\
\text { сервер/лок. }\end{array}$ \\
\hline \multicolumn{4}{|l|}{ 3.3. Справочники } \\
\hline $\begin{array}{l}\text { 3.3.1. Отраслевые производ- } \\
\text { ственно-практические (для спе- } \\
\text { циалистов данной отрасли науки, } \\
\text { техники) }\end{array}$ & 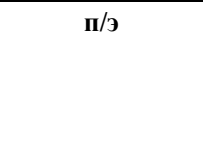 & 1/все IP & $\begin{array}{c}\text { ЧЗ } \\
\text { сервер/лок. }\end{array}$ \\
\hline $\begin{array}{l}\text { 3.3.2. Специальные (формул, ве- } \\
\text { личин и т.д.) }\end{array}$ & II/3 & 1/все IP & $\begin{array}{c}\text { ЧЗ/копирование } \\
\text { сервер/лок. }\end{array}$ \\
\hline 3.3.3. Каталоги библиотек & э & все IP & откр. \\
\hline \multicolumn{4}{|l|}{ 4. Информационные издания } \\
\hline $\begin{array}{l}\text { 4.1. Научно-вспомогательная биб- } \\
\text { лиография (БД - электронные) }\end{array}$ & 3 & все IP & лок. \\
\hline $\begin{array}{l}\text { 4.2. Ретроспективные указатели } \\
\text { по видам публикаций (отрасле- } \\
\text { вые, тематические) }\end{array}$ & э & все IP & лок. \\
\hline $\begin{array}{l}\text { 4.3. Обзорные издания (рефера- } \\
\text { тивные, аналитические, прогно- } \\
\text { стические обзоры) }\end{array}$ & э & все IP & лок. \\
\hline \multicolumn{4}{|l|}{ 5. Учебные издания } \\
\hline $\begin{array}{l}\text { 5.1. Учебные пособия (курсы } \\
\text { лекций, спецкурсы) }\end{array}$ & II/3 & 5-10/все IP & $\begin{array}{l}\text { ОД/Аб } \\
\text { лок. }\end{array}$ \\
\hline $\begin{array}{l}\text { 5.2. Практикумы (сборники за- } \\
\text { дач, лабораторных и практиче- } \\
\text { ских работ, задания) }\end{array}$ & II/3 & 5-10/все IP & $\begin{array}{l}\text { ОД/Аб } \\
\text { лок. }\end{array}$ \\
\hline
\end{tabular}


Продолжение таблицы 2

\begin{tabular}{|c|c|c|c|}
\hline \multirow[b]{2}{*}{ Виды изданий } & Форма & Количество & \multirow{2}{*}{$\begin{array}{c}\text { Размещение/ } \\
\text { уровень доступа }\end{array}$} \\
\hline & $\begin{array}{c}\text { печатная (п) / } \\
\text { электронная (э) }\end{array}$ & $\begin{array}{l}\text { экземпляров } * / \\
\text { точек доступа** }\end{array}$ & \\
\hline \multicolumn{4}{|l|}{ II. Журналы } \\
\hline $\begin{array}{l}\text { 1. Научные издания (издания } \\
\text { учреждений РАН, научных об- } \\
\text { ществ: труды, учёные записки и } \\
\text { др.) }\end{array}$ & II/3 & 1/все IP & $\begin{array}{l}\text { ОД/Аб } \\
\text { лок. }\end{array}$ \\
\hline $\begin{array}{l}\text { 1.2. Научно-технические и науч- } \\
\text { но-практические издания }\end{array}$ & II/3 & 1/все IP & $\begin{array}{c}\text { ОД/Аб } \\
\text { лок. }\end{array}$ \\
\hline \multicolumn{4}{|l|}{ 2. Информационные издания } \\
\hline 2.1. Реферативные издания & э & все IP & лок. \\
\hline $\begin{array}{l}\text { 2.2. Обзорная информация, экс- } \\
\text { пресс-информация }\end{array}$ & 3 & все IP & лок. \\
\hline \multicolumn{4}{|l|}{$\begin{array}{l}\text { III. Неопубликованные доку- } \\
\text { менты. См. } 1.4\end{array}$} \\
\hline \multicolumn{4}{|l|}{$\begin{array}{l}\text { IV. Электронные документы } \\
\text { на съёмных носителях }\end{array}$} \\
\hline $\begin{array}{l}\text { 4.1. Те же, что в разделе I (пол- } \\
\text { ностью) }\end{array}$ & 3 & 1 & Y3 \\
\hline $\begin{array}{l}\text { 4.2. Архивы электронных перио- } \\
\text { дических изданий }\end{array}$ & э & 1 & प3 \\
\hline \multicolumn{4}{|c|}{$\begin{array}{l}\text { Примечания: } \\
\text { * каждый экземпляр является точкой доступа к конкретному печатному изданию; } \\
\text { ** каждый IР-адрес является точкой доступа к электронному изданию; ОД - открытый доступ } \\
\text { к фонду печатных документов; Аб - выдача на абонемент; ЧЗ - выдача в читальный зал; откр. - } \\
\text { открытый доступ к электронным ресурсам; лок. - доступ к электронным ресурсам только с IP- } \\
\text { адресов локальной сети НИИ (открытый/локальный доступ зависит от условий приобретения } \\
\text { издания). }\end{array}$} \\
\hline
\end{tabular}

Таким образом, использование стратегических документов, взаимно дополняющих друг друга, позволяет:

более точно моделировать систему ИБР конкретного НИИ с учётом актуальных для него критериев отбора; 
включать в систему фондов профильные издания в наиболее удобной для учёных форме;

минимизировать накопление малоспрашиваемых документов.

Основная функция этой системы - формирование целостной и неразрывной документно-информационной среды конкретного НИИ.

Olga Levchenko, Head, Information and Library Center, Russian Academy of Sciences Institute of Solid State Physics;

olevch@issp.ac.ru, library@issp.ac.ru

2, Institutskaya st., 142432 Chernogolovka, Moscow Region, Russia 